\title{
REFLEXÕES LITERÁRIAS E FILOSÓFICAS NA BASE DE "OS GÊNEROS DO DISCURSO": CONSIDERAÇÕES PARA O ENSINO DE ESCRITA
}

\section{LITERARY AND PHILOSOFICAL REFLECTIONS ON "THE SPEECH GENRES'" CORE: CONSIDERATIONS FOR THE TEACHING OF WRITING}

\section{Lucas Vinicio de Carvalho Maciel ${ }^{*}{ }^{* *}$}

\section{RESUMO}

Objetiva-se, neste artigo, refletir acerca de aspectos literários e filosóficos que embasam o ensaio "Os gêneros do discurso" de Bakhtin. Essa reflexão se mostra oportuna, pois, passados 20 anos do lançamento dos "Parâmetros Curriculares Nacionais: terceiro e quarto ciclos: língua portuguesa" (BRASIL, 1998), o texto bakhtiniano que lhe serviu de base continua a fomentar documentos oficiais e políticas públicas acerca do ensino de escrita no Brasil. Desse modo, divisar facetas pouco exploradas da reflexão bakhtiniana pode levar a se repensar os gêneros do discurso e, por consequência, seu ensino.

Palavras-chave: gêneros do discurso; ensino; escrita.

\section{ABSTRACT}

The aim of this paper is to reflect on the literary and philosophical aspects that are the basis of Bakhtin's essay "Speech genres". This reflection is appropriate for this moment, since 20 years after the release of the "National Curricular Parameters: third and fourth cycles: Portuguese" (BRASIL, 1998), the Bakhtinian text that is on its basis continues fostering official documents and public policies for the teaching of writing in Brazil. Thus, outlining aspects yet under-explored of the Bakhtinian reflection may lead us to reassess speech genres and, consequently, its teaching.

Keywords: speech genres; teaching; writing.

\section{INTRODUÇÃO}

No Brasil vários documentos oficiais destacam a importância dos gêneros do discurso para o ensino de língua portuguesa, como exemplifica emblematicamente por sua importância e repercussão os "Parâmetros Curriculares Nacionais: terceiro e quarto ciclos: língua portuguesa" (doravante PCN), lançados em 1998 (BRASIL,

\footnotetext{
* Universidade Federal de São Carlos, UFSCar, São Carlos, SP, Brasil. lucasvcmaciel@yahoo.com.br.

** Mestre e doutor em Linguística Aplicada pela Universidade Estadual de Campinas (Unicamp)

Orcid: https://orcid.org/0000-0002-0959-4285
} 
1998). Desde então, a questão do ensino de escrita a partir de uma abordagem dos gêneros discursivos continua a permear políticas públicas, refletindo-se, por exemplo, na exigência imposta pelo Programa Nacional do Livro Didático de que os livros didáticos comtemplem uma diversidade de gêneros discursivos. Também documentos oficiais, como a recente Base Nacional Comum Curricular (BRASIL, 2017; 2018), reiteram a importância dos gêneros discursivos para o ensino.

A propósito, justamente esse relevo dado ao ensino de escrita por meio dos gêneros discursivos é que parece ter levado o ensaio "Os gêneros do discurso" ([1952-1953]) a se tornar um dos mais conhecidos textos de Bakhtin no Brasil. Mas a popularidade do ensaio bakhtiniano talvez decorra, também, de outro aspecto: trata-se do texto aparentemente mais "linguístico" do estudioso russo, ao passo que boa parte de sua produção é voltada a outros aspectos: literários ou mesmo filosóficos. ${ }^{1}$

As citadas razões podem explicar por que linguistas e educadores voltaram suas atenções especialmente a este texto bakhtiniano, que mais ou menos marcadamente embasa as muitas formas de ver e de se propor ensinar gêneros do discurso. Em coletâneas como, por exemplo, o livro "Gêneros: teorias, métodos, debates" (2005), organizado por Adair Bonini, Desirée Motta-Roth e José Luiz Meurer, observa-se a proficuidade do conceito de gênero, encarado de modo diverso por diferentes perspectivas linguísticas.

Rojo (2005), por sua vez, nota que, embora partam, explícita ou implicitamente, da noção bakhtiniana de gêneros discursivos, esse conceito pode ser apropriado de modo diverso por diferentes correntes teóricas, como as anglófona e francófona ${ }^{2}$. Também no Brasil o conceito de gêneros discursivo recebeu tratamentos distintos. Autores como Marcuschi (2005) e Koch (2006) assimilaram o conceito de gênero discursivo a suas reflexões, matizando-o com cores próprias da Linguística Textual, inclusive optando pela expressão "gêneros textuais". Posicionando-se contrariamente a essa corrente, Côrrea (2013), por exemplo, julga mais adequada a expressão "gêneros discursivos", que, ao revés da perspectiva textual, resguardaria a dinamicidade e a heterogeneidade próprias dos gêneros.

1. Reflexamente a fama do ensaio "Os gêneros do discurso" faz com que este seja um dos escritos do Círculo de maior circulação no campo linguístico, possivelmente junto à obra "Marxismo e filosofia da linguagem", a qual, segundo Sipriano e Gonçalves (2018, p. 132), é "certamente uma das obras mais lidas do Círculo" no Brasil.

2. Aliás, Rojo (2005, p. 185, grifo do autor) assinala haver uma diferença entre "duas vertentes metatoricamente diferentes" as quais nomeia como "teoria de gêneros do discurso ou discursivos e teoria de gêneros de texto ou textuais". A exemplo da autora, também entendemos se tratar de perspectivas diferentes e optamos pela primeira, a dos "gêneros do discurso" ou dos "gêneros discursivos", conforme argumentamos no presente artigo. 
Além dos argumentos apontados por Côrrea e já marcando nosso posicionamento, lembramos que a Linguística Textual volta seu olhar muito mais para a materialidade do texto, observando aspectos como coesão, coerência, intencionalidade e aceitabilidade, informatividade, situacionalidade e intertextualidade. Mesmo quando por esses aspectos se pretende ir além do texto, este é ainda a base de onde se busca lançar um olhar para fora. Bem diferente é a perspectiva bakhtiniana, em que se almeja em primeiro lugar entender o homem na vida e, no âmbito desta, a importância da linguagem verbal. Busca-se compreender o homem e, para tal, se divisa na linguagem verbal um caminho profícuo. Da vida se chega ao texto sempre materializado em um gênero discursivo; não o contrário.

Percebe-se, assim, que o texto "Os gêneros do discurso" tem suscitado leituras múltiplas e sua assimilação nos $\mathrm{PCN}$ ao que parece não se deu de modo homogêneo. Pouco após sua publicação, já apareceram críticas à maneira como este documento político-institucional apreendeu e buscou transmitir a noção de gêneros discursivos. Gomes-Santos (2004), por exemplo, problematiza especialmente o modo como são mobilizados no documento oficial, nem sempre com a devida propriedade, conceitos bakhtinianos coadunando-os a conceitos bastante diversos, quando não até mesmo opostos.

A forma como a noção de gêneros discursivos foi apreendida pelos $\mathrm{PCN}$ e a riqueza dos debates teóricos a respeito permitem indicar, depois de mais de 20 anos de lançamento dos parâmetros, a importância de se repensar o conceito de gêneros discursivos que os embasam.

Como atestam as obras já citadas, a reflexão a respeito dos gêneros discursivos e de seu ensino é profícua no Brasil. Nesse cenário, o intuito desse artigo é se somar a essas reflexões, buscando divisar aspectos que, julgamos, parecem pouco considerados quando se pretende entender - e a partir daí ensinar - o conceito de gêneros discursivos. Para tanto, realizaremos uma análise do conceito de gêneros discursivos pautando-nos especialmente nas obras do Círculo de Bakhtin, buscando desvelar aspectos literários e filosóficos que sustentam o ensaio bakhtiniano. Aspectos que, a nosso ver, podem levar a se repensar os gêneros e seu ensino.

\title{
2. A IMPORTÂNCIA DA LITERATURA PARA COMPREENDER “OS GÊNEROS DO DISCURSO" NO CONJUNTO DA OBRA BAKHTNIANA
}

\author{
Observa Rojo (2005, p. 194): \\ O texto de 1953 [leia-se "Os gêneros do discurso"], em minha opinião, é uma formalização \\ explícita (e de divulgação) - incompleta e nem tão bem acabada - das ideias disponíveis no
}


Círculo, desde o início. Algumas abordagens anteriores a este texto, por exemplo Bakhtin (1934-1935), dizem mais sobre o que são e como funcionam os gêneros e de maneira mais aprofundada e complexa.

A propósito, também já observamos (MACIEL, 2011) que o texto "Os gêneros do discurso" pode ser mais bem compreendido, caso se considerem também outros textos do Círculo. Porém, além disso, pretendemos enfatizar no presente artigo a importância da literatura nas reflexões bakhtinianas.

A preocupação com as questões estéticas está presente desde os primeiros textos de Bakhtin, como ilustra "Arte e responsabilidade" (1919). Mesmo em "Para uma filosofia do ato" (1919/1921), um texto de viés mais filosófico, a literatura aparece como material primordial para entendimento da vida, do homem.

Essa preponderância do interesse pela literatura na obra de Bakhtin é notória, sendo várias obras dedicadas exclusivamente à literatura, como, por exemplo, os textos de grande fôlego: "O autor e a personagem na atividade estética" ([192-]), "O problema do conteúdo, do material e da forma na criação literária" ([1924]), "Problemas da obra de Dostoiévski" (1929) - depois renomeada "Problemas da poética de Dostoiévski" em 1963 -, "O discurso no romance" (1935-1936), "A cultura popular na Idade Média e no Renascimento: o contexto de François Rabelais" (1965).

Em meio a tantos textos voltados à literatura, poucos textos do Círculo aparentemente escapam a essa predileção pelos exemplos literários. Poder-se-ia lembrar-se de "Marxismo e filosofia da linguagem" e, claro, de "Os gêneros do discurso".

Quanto ao primeiro, cuja autoria talvez seja da pena de Volóchinov e não de Bakhtin, basta-nos dizer, por não ser o escopo deste artigo, que também nele abundam exemplificações com textos literários (cf. MACIEL, 2014); o que, a propósito, é uma constante nos textos do Círculo (cf. MACIEL, 2016).

Já quanto propriamente ao texto "Os gêneros do discurso", parece comum imaginar que nele o espaço reservado à literatura seja diminuto. Isso ocorre, possivelmente, porque quando se vai ler o texto bakhtiniano, já se sabe de antemão que a partir do ensaio do pensador russo se alicerçam propostas didáticas que englobam uma miríade de gêneros. De acordo com o propugnado pelos PCN (BRASIL, 1998), por exemplo, o ensino de produção textual ganhou novos ares, indo além do "texto dissertativo", para englobar vários outros gêneros discursivos, como atestam as recentes coleções de livros didáticos aprovadas pelo PNLD (BRASIL, 2016). 
Todavia gostaríamos de lembrar que o texto "Os gêneros do discurso" é expressão de um caminho de pesquisas traçado por Bakhtin. Um caminho que se inicia com reflexões sobre a posição do homem na vida, procurando entender essa posição através dos limites e intersecções entre a vida e a arte, entre a ética e a estética.

Essa questão central aparece bastante claramente nos primeiros escritos de Bakhtin: "Arte e responsabilidade", "Para uma filosofia do ato" e "O autor e a personagem na atividade estética". Nesse último, Bakhtin já se aproxima claramente da literatura, sem, contudo, se distanciar de sua preocupação com o lugar do homem na vida. Ao discorrer sobre a relação entre a personagem e o autor, Bakhtin compara constantemente essa relação estética com a relação ética entre um homem e outro. Nesse texto, Bakhtin ainda advoga por um autor poderoso, que de sua distância exotópica possa dar acabamento (plástico, temporal, valorativo) à personagem, englobando-a no todo da obra. A estética se fundamentaria a princípio nessa possibilidade de acabamento: acabamento da personagem pelo autor ou narrador, acabamento material e formal da obra pelo autor-criador.

Diferentemente dessa posição estável e soberana do autor, na vida os homens não podem se "englobar" uns aos outros. A ninguém é dada a possibilidade de dar acabamento ao outro, pois este, se vivo, pode sempre mudar. A vida, por ser aberta, cobra uma posição ética dos sujeitos, que sempre podem mudar-se a si e ao mundo.

Por isso, prosseguindo em suas reflexões, Bakhtin mudará de opinião. Se em "O autor e a personagem na atividade estética" havia acusado Dostoiévski de não ser firme em sua posição exotópica frente às personagens, em seu estudo dedicado apenas a Dostoiévski (1929/1963), considerará que a posição do autor dostoievskiano ao lado das personagens é uma inovação que contribui para uma nova forma de romance, a que denominará "polifônico"3.

E é justamente por seu interesse pelas inovações que vislumbra na prosa dostoievskiana que Bakhtin procurará entender o papel do desenvolvimento histórico dos gêneros discursivos que foram sendo absorvidos e transformados ao se integrarem no romance, um gênero que tem por característica englobar outros. Assim, o interesse de Bakhtin pela questão dos gêneros discursivos passa por seu intento de compreender a prosa romanesca, especialmente a dostoievskiana.

3. "A voz do herói sobre si mesmo e o mundo é tão plena como a palavra do autor; não está subordinada à imagem objetificada do herói como uma de suas características, mas tampouco serve de intérprete da voz do autor. Ela possui independência excepcional na estrutura da obra, é como se soasse ao lado da palavra do autor, coadunando-se de modo especial com ela e com as vozes plenivalentes de outros heróis". (BAKHTIN, 2011 [1963], p. 5, grifo do autor) 
Também em outras obras - dedicadas ao estudo da literatura, convém lembrar - Bakhtin destacará a importância dos gêneros discursivos, como, por exemplo, em seu estudo sobre o discurso no romance (BAKHTIN, [1935-1936]), em que o pensador russo versará sobre a pluralidade de gêneros como uma característica do heterodiscurso (cf. MACIEL, 2018).

Assim, quando chega ao texto de 1952-1953, Bakhtin já havia flertado longamente com a questão dos gêneros discursivos, analisando-os, sobretudo, no campo da literatura. Atentos a essa trajetória intelectual de Bakhtin, examinemos o ensaio "Os gêneros do discurso".

Na primeira seção do texto, "O problema e sua definição", Bakhtin esboçará importantes questões: (i) os três elementos constitutivos do enunciados, quais sejam: conteúdo temático, construção composicional e estilo; (ii) a definição de gêneros como tipos relativamente estáveis de enunciado; (iii) a diversidade funcional dos gêneros - da réplica monovocal ao romance de vários tomos -; diversidade essa que complicaria a busca por um parâmetro definidor do que seria o gênero; (iv) a distinção entre gêneros primários e secundários e (v) a influência dos gêneros discursivos nos estilos individuais.

Não se trata de rol exaustivo, mas de aspectos que se destacam desta primeira - e por que não lembrar pequena - parte do texto. Essas questões são as que provavelmente mais habitam as divulgações da "teoria" bakhtiniana, sobretudo aquelas voltadas a discussões ou propostas pedagógicas.

Sem negar a importância e produtividade desses temas a diferentes áreas do conhecimento, destacamos, todavia, que ao final dessa seção Bakhtin escorrega para o campo da literatura. Isso porque toda a discussão prévia parece conduzida a chegar a um ponto: a importância de se entender os gêneros do discurso em face de sua relevância no desenvolvimento do estilo individual. Nas palavras do autor:

Desse modo, tanto os estilos individuais quanto os da língua satisfazem aos gêneros do discurso. Um estudo mais profundo e amplo destes é absolutamente indispensável para uma elaboração eficaz de todas as questões da estilística (BAKHTIN, 2016 [1951-1952], p. 21).

A segunda parte do ensaio tem por subtítulo "O enunciado como unidade da comunicação discursiva. Diferença entre essa unidade e as unidades da língua (palavras e orações)". Essa segunda e bem mais longa seção será dedicada a uma análise minuciosa das diferenças entre oração e enunciado. Embora de modo não esquemático, Bakhtin elencará diversas diferenças. A oração prescinde da alternância de sujeitos, permanecendo em um mesmo contexto verbal, não suscita resposta, não possui autor e é desprovida de entonação. Por oposição, o enunciado 
pressupõe a alternância de sujeitos, é envolto por um contexto extraverbal, suscita resposta, tem autor e entonação.

Essa entonação, segundo Bakhtin, mostra a relação do falante com o objeto semântico do enunciado e é influenciada pelas nuanças próprias do gênero em que o enunciado é materializado. Mas não só. Além disso e de modo destacado, Bakhtin observa que a concepção do enunciado e, claro, sua entonação são direcionados ao destinatário típico daquele gênero do discurso.

Bakhtin chega a essa questão para observar:

A concepção do destinatário do discurso (como o sente e imagina o falante ou quem escreve) é uma questão de enorme importância na história da literatura. Cada época, cada corrente literária e estilo ficcional, cada gênero literário no âmbito de uma época e cada corrente têm como características suas concepções específicas de destinatário da obra literária, a sensação especial e a compreensão de seu leitor, ouvinte, público, povo. O estudo histórico das mudanças dessas concepções é uma tarefa interessante e importante. Mas para sua elaboração eficaz faz-se necessária uma clareza teórica na própria colocação do problema. (BAKHTIN, 2016 [1952-1953], p. 67)

É justamente essa clareza teórica que Bakhtin parece tentar colocar neste texto. Esse problema, essa questão é, segundo suas próprias palavras, "de enorme importância para a história da literatura".

Assim, embora passe por questões mais gerais, a literatura parece ser sempre um pano de fundo das discussões, um locus teórico para o qual estão dirigidas muitas de suas incursões epistemológicas. Isso não invalida, claro, as inúmeras possibilidades que o texto bakhtiniano pode oferecer a reflexões várias nos distintos campos do conhecimento humano. Enfatizamos apenas uma faceta por vezes esquecida e, a nosso ver, imprescindível da reflexão bakhtiniana: a literatura como objeto privilegiado de estudo.

Um objeto que, mesmo quando aparentemente não tão presente, continua dando o tom das reflexões bakhtinianas, até porque há de se reconhecer que teoria e dados vivem em comunhão. Não existe teoria que não seja influenciada pelos dados que analisa e os dados preferenciais de Bakhtin provêm da literatura (cf. MACIEL, 2016).

Apenas para ilustrar a discussão, atente-se, por exemplo, para o modo de configuração típico de relações dialógicas presentes em gêneros literários (MACIEL, 2016), nos quais, por vezes, além das relações dialógicas externas há também peculiares relações dialógicas internas (MACIEL, 2017), por meio das quais se relacionam vozes de autor, narrador e personagens. $\mathrm{O}$ fato de essas vozes provirem de um mesmo autor - diferentemente, por exemplo, de um texto acadêmico em que as vozes citadas pertencem a diferentes sujeitos - é traço característico dos gêneros 
literários. Em um diálogo representado em uma narrativa literária vozes ficcionais derivam de um mesmo sujeito, de um mesmo autor. Já em um texto acadêmico, espera-se que o autor colacione em sua exposição vozes de outros autores, de outros sujeitos reais. Possível observar, portanto, algumas relações dialógicas próprias da literatura, em que se espera e aceita a representação de vozes ficcionais criadas por um mesmo sujeito, autor. Em gêneros não literários, o comum é que as vozes citadas pertençam a diferentes sujeitos.

Essa diferença é uma das razões a explicar a predileção do Círculo pela análise de textos literários, sendo essa apenas uma das tantas questões bakhtinianas por vezes desconsideradas no ensino dos gêneros. Não se trata de crítica, mas de destacar que a questão dos gêneros discursivos aparece no horizonte intelectual de Bakhtin como profícuo caminho para a compreensão da literatura. Por isso, quando da apropriação do texto "Os gêneros do discurso", imprescindível considerar esse papel fundamental da literatura no pensamento bakhtiniano, o que pode levar a uma mais profunda compreensão desse pensamento, e, por extensão, a novos olhares para o ensino dos gêneros.

\section{REFLEXÕES FILOSÓFICAS E OS GÊNEROS DO DISCURSO NOS ESTUDOS BAKHTINIANOS}

Outro aspecto a se destacar é o modo pelo qual as reflexões filosóficas desenvolvidas por Bakhtin auxiliam a entender sua concepção dos gêneros do discurso.

Dentre os primeiros textos de Bakhtin, merece destaque o assim denominado pela crítica "Para uma filosofia do ato" (BAKHTIN, 1919/1921) ${ }^{4}$. Nesse estudo, o pensador discorre sobre a posição do homem na vida, cuja

participação real de um ponto concretamente único no Ser engendra o peso real do tempo e o valor intuitível-palpável do espaço, torna as fronteiras pesadas, não-fortuitas e válidas: o mundo como um todo unitário e único, real e responsavelmente experimentado (BAKHTIN, 1919/1921, p. 75$)$.

Observa-se, assim, uma preocupação filosófica sobre o lugar do homem na vida. Homem concebido como responsável, pois considerado em seu lugar único na existência. Um lugar que somente ele pode e ocupa naquele momento - histórico, temporal, espacial e valorativo. Em dado ponto único da existência humana, o

4. Também nomeado "Para uma filosofia do ato responsável", por Miotello e Faraco (BAKHTIN, 2010) ou "Para uma filosofia da ação responsável" por Ponzio (BAKHTIN, 1997). 
tempo e o lugar abstratos se tornam concretos para determinado homem; o tempo e o lugar ganham peso e valor irrepetíveis. Desse lugar único, o homem, ainda que o queria, não pode escusar sua responsabilidade frente à vida aberta, ainda em desenvolvimento.

Seria de se apontar, aliás, que, para ilustrar sua discussão sobre essa questão filosófica, Bakhtin recorre à literatura: mais precisamente a diferentes versões do poema "Separação" de Púckhin. Mais uma vez, a literatura adentra - ou melhor, permanece - nas reflexões do pensador russo.

Porém, mais do que isso, é de se frisar que as premissas filosóficas lançadas nesse texto acompanharam longamente Bakhtin. Assim, quando propõe, em "Problemas da poética de Dostoiévski", que se vá além da linguística em direção ao que denomina "metalinguística", Bakhtin deixa antever que a linguística não conseguiu ir além do código linguístico ou mesmo do texto. A linguística não teria avançado suficientemente em prol de um entendimento da linguagem verbal como ato humano.

Na concepção bakhtiniana a linguagem importa tão somente e primordialmente enquanto ato humano, por isso para estudá-la deve-se ir da vida à linguagem verbal, quando menos do contexto ao texto. Inversamente, porém, parecem ser esforços teóricos e práticos que ainda partem do texto para, numa abordagem supostamente bakhtiniana, chegar a um contexto.

Pensemos no ensino de gêneros discursivos. Em substituição ou em complementação às abordagens oriundas da Linguística Textual dos anos 1980 e 1990, especialmente a partir dos anos 2000 é mais comum encontrar abordagens ditas bakhtinianas. Conceitos como "dialogismo", "conteúdo temático", "estrutura composicional", "estilo" e "signo ideológico" passam a habitar inúmeras publicações acadêmicas, além de permearem documentos oficiais como os PCN. Documentos esses que, por sua vez, impactam a produção de livros didáticos e, presumivelmente, práticas de docentes.

Cabe, de todo modo, uma questão: o ensino dito bakhtiniano é mesmo um ensino "metalinguístico", se não qual o propôs Bakhtin, mas pelo menos próximo ao que ele delineou em seus escritos?

Suponhamos um exemplo hipotético, nem por isso implausível. Não seria raro encontrar hoje em materiais didáticos propostas para ensino de um gênero como "receita culinária". Ora, trata-se de um tema cotidiano, supostamente capaz de ilustrar a preocupação escolar em se relacionar com a vida do aluno ao mesmo tempo em que atende a orientações oficiais e acadêmicas que apregoam a importância de se trabalhar com uma diversidade de gêneros. 
Desconsideremos, por não ser o escopo deste artigo, se ensinar o gênero receita culinária pode ser interessante ou não ao alunado. Prossigamos, imaginando uma possível abordagem bakhtiniana desse gênero. Partindo dos elementos constitutivos do enunciado, poder-se-ia explorar a estrutura composicional típica do gênero, neste caso ainda facilitada por uma frequente separação visual na medida em que há comumente três espaços composicionais claramente marcados: "título", "ingredientes" e "modo de preparo".

Caberia ainda explorar, por óbvio que seja, o conteúdo temático desses dois campos composicionais: nos "ingredientes" estaria listada a matéria-prima da receita, enquanto no "modo de preparo" descrever-se-ia o "como fazer". Mesmo o estilo poderia ser explorado nesse exemplo, mencionando-se que no "modo de preparo" é comum a ocorrência de verbos no modo imperativo.

Esse exemplo hipotético - mas provavelmente bastante real e comum pode mostrar certa abordagem dos gêneros discursivos a partir de uma perspectiva bakhtiniana. Por certo, poderia haver críticas, reconhecendo que se caberia ainda falar sobre o contexto extraverbal que envolve essa receita.

$\mathrm{Na}$ verdade, entendemos ser por esse contexto que se deveria ter começado, não o contrário. Caberia questionar os alunos e refletir com eles primeiramente sobre para que serve uma receita, quem a faz comumente hoje, quem a degusta (São os mesmos que preparam? São outros?). Será que hoje é comum que jovens e adolescentes - como se fossem todos iguais, ideológica e socialmente - cozinhem? Se não, quem cozinha? É uma tarefa doméstica ou profissional? Masculina ou feminina? Como as receitas são hoje acessadas, difundidas? Quem são seus autores? Há "autores" de receitas? São essas as questões primeiras que deveriam levar da vida ao texto e não deste a um suposto contexto. É entendendo a atividade verbal no caso, a receita culinária - como um ato da vida que o sujeito conseguirá entender que a linguagem (sempre estruturada em gêneros) é fundamental à vida.

Além disso, seria importante propor uma retomada da história do gênero, assim como Bakhtin fez quando de seu estudo do gênero romance - o que reforça, por sua vez, a importância da literatura no pensamento bakhtiniano. No caso da receita, por exemplo, seria possível conjecturar que as receitas eram inicialmente divulgadas oralmente. Depois é que essas receitas passaram a ser transcritas para o papel. Conforme observa Demeterco (2003, p. 86-87):

5. A propósito, Rojo (2006) também realizando análise do gênero receita culinária observa esses espaços composicionais. 
[é] a partir do século XIV é que se tem notícia das primeiras receitas escritas em livros de cozinha, desde Apicius, na Roma antiga, a quem se atribui a autoria do mais antigo livro de cozinha (De re coquinaria, Da cozinha) cuja primeira edição data do final do século XV.

Já em terras nacionais, observa Barros (2016, p. 11) que no "campo da culinária destaca-se a obra Ccozinheiro Imperial (1840), primeiro livro editado no Brasil e com conteúdo voltado para a cozinha que se fazia no país".

Nessa retrospectiva história - que apenas ilustramos - seria interessante observar que cada receita, cada livro de receitas dialoga com outras receitas, outros livros, outras vozes. Apenas para mencionar um aspecto, poder-se-ia lembrar que o Ccozinheiro Imperial é, de certa forma, uma resposta à imposição dos ingredientes e modo de preparo europeus, buscando-se uma culinária mais genuinamente nacional.

Além disso, nessa retrospectiva histórica, seria o caso de se mostrar como o gênero se amolda às circunstâncias histórias. Uma receita culinária hoje é, muitas vezes, acessada em plataformas digitais, apresentando-se por vezes com caráter multimodal: ou seja, além do texto, é comum o recurso a imagens e, inclusive, a vídeos. Essas novas possibilidades impactam por certo o gênero. Também é muito comum atualmente que as receitas, além dos espaços composicionais "título", "ingredientes" e "modos de fazer", apresentem seções destinadas a "rendimento", "tempo de preparo" e "custos".

Veja-se o exemplo de uma receita disponível na internet: 


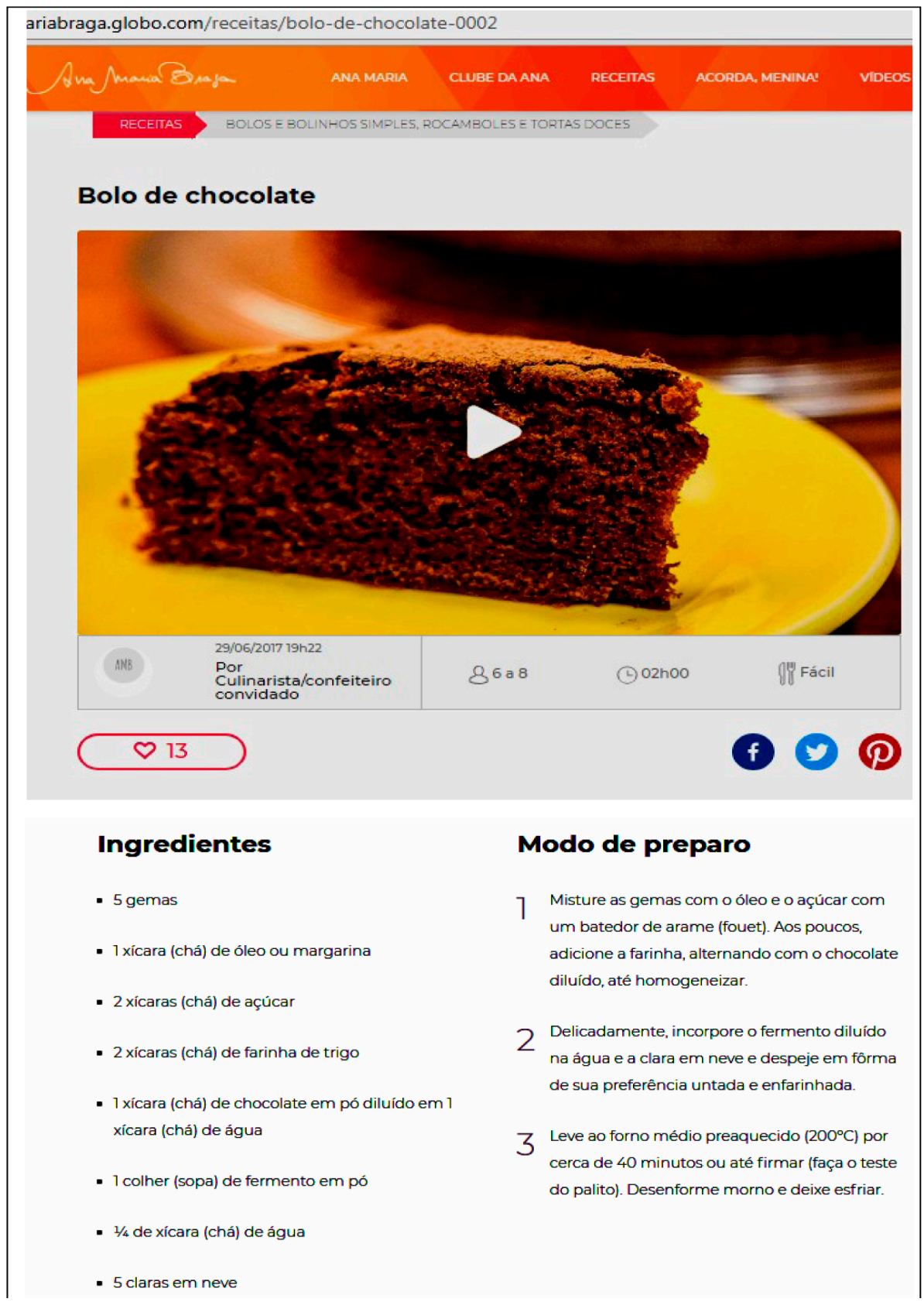

Imagem 1: PrintScreen do site Ana Maria Braga

Fonte: https://anamariabraga.globo.com/receitas/bolo-de-chocolate-0002 
Por que essas novas seções aparecem? Para responder a essa questão é preciso olhar o desenvolvimento histórico do gênero.

Nas primeiras receitas não havia uma distinção composicional entre ingredientes e modo de preparo, como se exemplifica com a receita a seguir retirada do já citado De re coquinaria:

III. <ROSATVM ET VIOLATIVM>. 1. Rosatum sic facies: folia rosarum, albo sublato, lino inseris et sutilis facias, et vino quam plurimas infundes, ut septem diebus in vino sint. post septem dies rosam de vino tollis, et alias sutiles recentes similiter mittis, ut per dies septem in vino requiescant, et rosam eximis. similiter et tertio facies, et rosam eximis, et vinum colas, et, cum ad bibendum voles uti, addito melle rosatum conficies. sane custodito ut rosam a rore siccam et optimam mittas. Similiter, ut supra, et de $<$ viola $>$ violatium facies, et eodem modo melle temperabis. (Disponível em: http://www.gutenberg.org/files/16439/16439$\underline{\mathrm{h} / 16439-\mathrm{h} \cdot \mathrm{htm})}{ }^{6}$

Provavelmente a necessidade de diferenciar ingredientes e modo de preparo surge com uma nova sociedade em que os ingredientes não estão à mão, sendo necessário previamente comprá-los e estocá-los para quando, oportunamente, virem a ser conjugados no preparo da receita. Ou seja, a distinção composicional entre "ingredientes" e "modo de preparo" surge quando o ato de cozinhar precisa estar organizado em um dia com horas, se não contadas, pelo menos, organizadas em prol de certa "produtividade". Possivelmente isso ocorra e se intensifique em uma sociedade cada vez mais industrial em que os ingredientes já não são aqueles colhidos no quintal e os que cozinham - as mulheres? - precisam conciliar uma vida laboral com o trabalho doméstico. A premência de "administrar" o tempo parece ser também, sobretudo na modernidade mais recente, a razão do surgimento do espaço composicional "tempo de preparo".

Já o "rendimento" e o "custo" podem interessar tanto àqueles preocupados com quanto podem gastar no preparo de determinado prato quanto aos que almejam possíveis possibilidades de lucro. Em síntese, à medida que o desenvolvimento do modelo capitalista avança, o gênero receita culinária muda. É na vida, portanto, que se devem buscar as razões das mudanças históricas dos gêneros. E é pela vida que se inicia o trabalho para o ensino dos gêneros discursivos.

Portanto, por mais interessantes que sejam conceitos bakhtinianos como "conteúdo temático", "construção composicional" e "estilo", a mera consideração desses elementos constitutivos do enunciado, a nosso ver, não leva a um genuíno trabalho bakhtiniano de ensino de gêneros discursivos.

6. Mesmo livros de receitas mais recentes atestam a não divisão entre ingredientes e modo de preparo a exemplo de receitas reunidas de Cora Coralina (CORALINA, 2009). 
Para se refletir com base em outro gênero discursivo, pense-se que um artigo acadêmico possui espaços composicionais típicos - título, resumo, introdução, referencial teórico, análise, conclusões/resultados, referências - nos quais se desenvolve um conteúdo temático próprio - espera-se que os dados apareçam na análise e não nas referências, por exemplo - em um estilo (acadêmico) particular.

Todavia tal abordagem é, ainda, bastante textual, pois parte do texto e a ele se atém. Uma visada bakhtiniana, iniciar-se-ia questionando quem escreve artigos acadêmicos, para quem, com qual intuito. Questionar-se-ia qual o papel histórico desses gêneros: quando surgiram os artigos acadêmicos? Como se deu seu desenvolvimento histórico? Essas são questões primeiras e não secundárias no trabalho com o gênero. Não é depois de se trabalhar os elementos mais textuais dos gêneros que se deve pensar em sua realidade metalinguística, muitas vezes reduzida tão somente ao "contexto" em que o gênero se insere. No caso dos gêneros acadêmicos a importância dos aspectos metalinguísticos tem se tornado cada mais evidente com o desenvolvimento das pesquisadas enfeixadas sob a denominação de "letramentos acadêmicos", como bem observa, ilustrativamente, Fiad (2011).

Assim, uma abordagem realmente bakhtiniana parte da vida, buscando entender os gêneros como artefatos que conjugam os homens, em suas vidas singulares, e o correr histórico que impacta essas vidas, impondo mudanças nos gêneros discursivos por meio dos quais o homem se comunica e vive.

\section{CONSIDERAÇÕES FINAIS}

Sempre é de interesse (re)ler "Os gêneros do discurso", pois conforme o tempo passa novos olhares podem ser lançados a esse texto de Bakhtin, já que continuam sendo frutíferos, nomeadamente no Brasil, os estudos dedicados à obra do Círculo. Na infindável renovação dialógica das respostas a esse texto, propomos no presente artigo destacar a influência da literatura e da filosofia nas reflexões de Bakhtin que embasam "Os gêneros do discurso", o que pode levar a se repensar o ensino da escrita via gêneros discursivos.

Sem de modo algum pretender-se ser um roteiro de leitura ou uma orientação única à assimilação desse texto tão plural, objetivamos sublinhar dois aspectos importantes, mas talvez pouco considerados, para a compreensão da obra do pensador russo.

Um primeiro é ser a literatura um constante pano de fundo das reflexões de Bakhtin, que a ela volta, mesmo quando parece se distanciar. No caso de "Os gêneros do discurso", a discussão sobre os gêneros discursivos é conduzida em prol 
da diferenciação entre oração e enunciado, já que sobreleva como característica capital do enunciado o ser realizado em e influenciado por formas típicas dos gêneros discursivos. E, para Bakhtin, divisar as diferenças entre enunciado e oração é um caminho profícuo a contribuir para estudos mais eficientes no campo da estilística.

Assim, o estudo que Bakhtin realiza dos gêneros discursivos tem por escopo entender o papel desses gêneros no desenvolvimento da literatura, sobretudo no que diz respeito à questão estilística. Entender essa preocupação de Bakhtin talvez permita se olhar o ensaio "Os gêneros do discurso" de outro modo, pois o autor não realiza seu estudo propondo que seu texto sirva de base a propostas didáticas. Quando hoje isso é realizado, há de se ter algum cuidado para não se ver no texto de Bakhtin aquém ou além do que ele mesmo propugnou.

Além disso, a proposta bakhtiniana de compreensão dos gêneros do discurso precisa ser entendida dentro do interesse primeiro do autor por entender o lugar do homem na vida. Um lugar que pode ser apreendido pela linguagem verbal, a qual, por sua vez, só se realiza em um tempo e lugar único da vida necessariamente responsável e axiológica. Por isso, uma abordagem bakhtiniana de ensino de escrita de gêneros discursivos não é, por exemplo, aquela que tente entender e ensinar um gênero apenas como texto, ainda que abordado a partir, supostamente, de conceitos bakhtinianos como os elementos constitutivos do enunciado. A compreensão dos gêneros e as propostas de ensino de gêneros devem ir da vida ao gênero e não do gênero a vida, muitas vezes reduzida apenas a um "contexto".

\section{REFERÊNCIAS}

BAKHTIN, M. M. (1919/1921). Para uma filosofia do ato. Tradução não revisada, para fins didáticos e acadêmicos, realizada por Carlos Alberto Faraco e Cristovam Tezza. [S.I.: s.n.], [2005-2006].

BAKHTIN, M. M. (1919/1921). Para uma filosofia da ação responsável. In: Hacia una filosofia del acto ético. De los boradores y otros escritos. Trad. Augusto Ponzio. Puerto Rico: Anthropos, 1997.

BAKHTIN, M. M. (1919/1921). Para uma filosofia do ato responsável. Trad. aos cuidados de Valdemir Miotello e Carlos Alberto Faraco. São Carlos: Pedro \& João Editores, 2010.

BAKHTIN, M. M. ([1952-1953]). Os gêneros do discurso. In: Os gêneros do discurso. Organização, tradução, posfácio e notas Paulo Bezerra. São Paulo: Editora 34, 2016. 
BAKHTIN, M. M. (1963). Problemas da poética de Dostoiévski. Tradução Paulo Bezerra. 5. ed. (2. tiragem). Rio de Janeiro: Forense Universitária, 2011.

BRASIL. (1998). Parâmetros Curriculares Nacionais: terceiro e quarto ciclos: língua portuguesa. Brasília/DF: MEC/SEF.

BRASIL. (2016) Programa Nacional do Livro Didático (PNLD) 2017: língua portuguesa - ensino fundamental anos finais. Brasília, DF: MEC/SEF.

BRASIL. (2017). Base Nacional Comum Curricular: Educação Infantil e Ensino Fundamental. Brasília: MEC/SEB, 2017.

BRASIL. (2018). Base Nacional Comum Curricular: Ensino Médio. Brasília: MEC/SEB, 2018.

BARROS, B. R. N. (2016). Os livros de culinária como marco indenitário no Brasil. Trabalho de Conclusão de Curso em Biblioteconomia e Documentação. Instituto de Arte e Comunicação Social, UFF, Niterói.

CORALINA, C. (2009). Cora Coralina: doceira e poeta. São Paulo: Global.

CORRÊA, M. L. G. (2013). Bases teóricas para o ensino da escrita. In: Linguagem em (Dis) curso, Tubarão, SC, v. 13, n. 3, p. 481-513.

DEMETERCO, S. M. S. (2003) Sabor e saber: livros de cozinha, arte culinária e hábitos alimentares. Curitiba: 1902-1950. Tese de Doutorado em História. Setor de Ciências Humanas, Letras e Artes, UFPR, Curitiba.

FIAD, R. S. (2011). A escrita na universidade. Revista da ABRALIN, [S.I.] v. 10, n. 4, p. 357-369.

GOMES-SANTOS, S. N. (2004) A questão do gênero no Brasil: teorização acadêmico-científica e normatização oficial. Dissertação de Mestrado em Linguística Aplicada. Instituto de Estudos da Linguagem, Unicamp, Campinas.

ROJO, R. (2005). Gêneros discursivos e gêneros textuais: questões teóricas e aplicadas. In: MEURER, J. L.; BONINI, A.; MOTTA-ROTH, D. (Org.). Gêneros: teorias, métodos, debates. São Paulo: Parábola Editoria, p. 184-207.

ROJO, R. (2006). Alfabetização e letramento: sedimentação de práticas e (des)articulação de objetos de ensino. In: Perspectiva, Florianópolis, v. 24, n. 2, p. 569-596.

KOCH, I. V. (2006). Ler e compreender: os sentidos do texto. São Paulo: Contexto. 
MACIEL, L. V. C. (2011). Além de "Os gêneros do discurso". Cadernos de Estudos Linguísticos (Unicamp), v. 53, p. 27-38.

MACIEL, L. V. C. (2014). Relações dialógicas em narrativas. Tese de Doutorado em Linguística Aplicada. Instituto de Estudos da Linguagem, Unicamp, Campinas.

MACIEL, L. V. C. (2016). Relações dialógicas na vida e na representação literária. Letras de Hoje, v. 51, p. 194-201.

MACIEL, L. V. C. (2017). A (in)distinção entre dialogismo e intertextualidade. Linguagem em (dis)curso, v. 17, p. 137-151.

MACIEL, L. V. C. (2018). Considerações sobre heterodiscurso a partir de Dom Quixote. Bakbtiniana - Revista de Estudos do Discurso, v. 13, p. 100-116.

MARCUSCHI, L. A. (2005). Gêneros textuais: definição e funcionalidade. In: DIONISIO, A. P.; MACHADO, A. R.; BEZERRA, M. A. (Org.) Gêneros textuais e ensino. Rio de Janeiro: Lucerna.

MEURER, J. L.; BONINI, A.; MOTTA-ROTH, D. (Org.). (2005). Gêneros: teorias, métodos, debates. São Paulo: Parábola Editorial.

SIPRIANO, B. F.; GONÇALVES, J. B. C. (2018). A difusão do pensamento bakhtiniano no Ocidente: uma leitura dos contextos de recepção no Brasil. Eutomia, Recife, v. 21, n. 1 , p. $120-143$.

Recebido: 25/06/2019

Aceito: 28/08/2019

Publicado: 24/09/2019 